\title{
Effect of Cytokinins on Micropropagation of Moringa Oleifera Lam. and Genomic Stability Assessment Using Flow-Cytometry
}

\section{Rohit Bharati}

Czech University of Life Sciences Prague: Ceska Zemedelska Univerzita v Praze

\section{Moses Okao}

Czech University of Life Sciences Prague: Ceska Zemedelska Univerzita v Praze

\section{Katerina Hamouzová}

Czech University of Life Sciences Prague: Ceska Zemedelska Univerzita v Praze

Eloy Fernandez-Cusimamani ( $\nabla$ eloy@ftz.czu.cz )

Czech University of Life Sciences Prague: Ceska Zemedelska Univerzita v Praze https://orcid.org/0000-0001-7835-9310

\section{Research Article}

Keywords: Moringa oleifera, nodal explants, cytokinin, flow cytometry

Posted Date: January 13th, 2022

DOI: https://doi.org/10.21203/rs.3.rs-1238384/v1

License: (9) This work is licensed under a Creative Commons Attribution 4.0 International License. Read Full License 


\section{Abstract}

Moringa oleifera Lam. is a multipurpose medicinal plant of the family Moringaceae which has been widely utilized as a pharmaceutical remedy to treat a wide range of diseases. In addition, the tree has several applications in human nutrition as well as livestock feeding. M. oleifera is easily multiplied through epigeal germination (recalcitrant) but seed propagated plants are heterogeneous and take longer to reach fruit-bearing age. As an alternative, branch cuttings have been used but their establishment is erratic and often leads to reduced growth of the mother plant. Thus, to produce superior planting materials, in-vitro propagation has become paramount. As a result, several studies using a limited range of cytokinin have been undertaken to multiply $M$. oleifera through tissue culture. Otherwise, a study was conducted to examine the effect of five different cytokinins on in-vitro regeneration of this tree species. Results showed that nodal explants cultured on Murashige and Skoog (MS) medium supplemented with $1.0 \mathrm{mg} / \mathrm{L}$ 6-Benzylaminopurine (BAP) and subsequently rooted on basic MS media was the most optimal treatment. Furthermore, acclimatization of plantlets in sterile soil substrate and perlite $(1: 3 ; v / v)$ under transparent polythene sheet for 7 days resulted in survival rate of $100 \%$. Assessment of genetic fidelity using flow cytometry revealed that surface sterilization alongside cytokinin treatments produced plantlets that were genetically stable regardless of the growth regulator used. Thus, the in-vitro protocol developed in this study can be utilized for in-vitro studies and mass propagation of this imperative plant species.

\subsection{Introduction}

Moringa oleifera, drumstick or horseradish, is a well-known medicinal plant that belongs to the Moringaceae family. A minimum of 10 species of this family are reported to possess pharmacological properties (Olson et al., 2001), where M. oleifera is the most important one and is cultivated widely. It is mainly native to India and Pakistan, but its domestication has spread across Asia, Africa, South America, and other parts of the world (Ganatra et al., 2012, Maqsood et al., 2017, Pandey et al., 2011).

It is a valuable multipurpose tree as nearly every part of it can be eaten or used for pharmaceutical and industrial purposes. Its leaves, flowers and fresh pods can be consumed as vegetables as well as utilized as livestock feed, making it valuable from the food security point of view (Anjorin et al., 2010). Reportedly, Moringa leaves are endowed with $\beta$-carotene, protein, vitamin $\mathrm{C}$, calcium and potassium and act as a good source of natural antioxidants such as flavonoids, phenolics and carotenoids (Mehwish et al., 2021; Xiong et al., 2021; Daghaghele et al., 2021). On the other hand, various parts of the horseradish tree such as the leaves, root, bark, seed, flowers, and immature pods are found to have medicinal properties. The plant parts are reported to act as cardiac and circulatory stimulants and possess antitumor, antipyretic, antiepileptic, cholesterol-lowering, antioxidant, antidiabetic, hepatoprotective, antibacterial and antifungal properties (Anwar et al. 2007; Fahey, 2005). Thus, they are used in many traditional medicine formulations to treat different ailments, particularly in South Asia. For instance, Anwar et al. 2007 reported that a concoction containing Moringa gum and sesame oil is used to relieve headaches, fevers, intestinal complaints, dysentery, and asthma in addition to treating syphilis and rheumatism. In addition, 
Moringa has been found to enhance milk production for breastfeeding mothers (Siddhuraju and Becker, 2003).

Conventionally, Moringa is propagated through epigeal seed germination which is normally between 60 and 98 percent for fresh seeds (Nouman et al. 2012). However, seeds having a relatively longer juvenile phase and being heterogeneous in nature are not preferred (Jun-jie et al., 2017). In addition, the viability of seeds tends to decline rapidly (Fotouo-M et al., 2015). This phenomenon has been improved through vegetative propagation as Moringa can be propagated by stem cuttings where branch cuttings approximately one meter long are rooted and established in moist soil (Sharma and Raina, 1982; Islam et al., 2005; Ridzuan et al., 2020). However, stem cutting often affects yield and reduces the growth of the mother plant and at times, causes the death of the mother plant (Islam et al., 2005). To overcome these problems, plant tissue culture emerges as a better alternative to produce healthy plantlets without harming the mother plant within a shorter frame of time (Jamsheed et al., 2013).

Recently, numerous attempts have been made to propagate the plant by tissue culture with substantial progress. The progress includes shoot proliferation using nodal segment or callus supplemented with 0.5$3.0 \mathrm{mg} / \mathrm{L}$ BAP (6-benzylaminopurine), Kinetin and TDZ (Thidiazuron), alone or in combination, producing maximum average between 1.5-5.0 shoots (Gayathri et al., 2015; Forster et al., 2013; Marfori, 2010; Mathur et al., 2014; Ridzuan et al., 2018; Jun-jie et al., 2017). Considering the increasing demand, these numbers are not sufficient. Nevertheless, in a study by Saini et al., 2012, researchers were able to achieve a high number of shoots up to $9.0 \pm 1.0$ per explant. However, the study utilized seeds as explant, which are heterogeneous and are not the preferred choice of propagation material (Jun-jie et al.,2017). Moreover, the survival rate of ex-vitro transfer of the plants was $80 \%$, which could be improved, when compared with results that of Mathur et al., 2014 where a $95 \%$ success rate was achieved. Few modifications in existing in-vitro protocols such as Plant Growth Regulators (PGR) concentration and composition, light intensity and temperature could produce better results (Avila-Treviño et al., 2017). Despite these studies, an efficient and complete protocol for mass propagation of this plant is still limited.

One of the major setbacks of the tissue culture technique is the putative occurrence of genomic variability among regenerants also known as somaclonal variations (Rout et al., 2006;). Genomic alterations such as endo-polyploidy, amplification, or deletion of DNA sequence, polyteny are observed during somatic differentiation (Schoenfelder and Fox, 2015). These alterations could be triggered by various factors such as long exposure to PGR, age of the culture, adaptive stress of in-vitro system, etc (Delporte et al., 2013; Clarindo et al.,2008). Hence, the assessment of genomic aberrations is a crucial step to achieving successful micropropagation while preserving the desirable characters in the regenerants. Evaluations of genotypes at ploidy levels ensures in-vitro regenerants to possess an equivalent amount of Deoxyribonucleic acid (DNA) as the mother plant (Mamedes-Rodrigues et al., 2018). Flowcytometry is a fast and efficient method for DNA content estimation that has been utilized to access clonal fidelity in numerous plant species (Loureiro et al., 2007; Sliwinska et al., 2007; Zafar et al., 2019). 
To date, the related studies had employed a single or small set of cytokinins within a single experiment. However, in this study we had used the major cytokinins (BAP, TDZ, 2iP, Kinetin, and Zeatin) within a single experimental setup, to avert any experimental variations. Hence, this study aims to delve into the effects of major cytokinins within a single experimental setup. Additionally, it also aims to develop an efficient and complete micropropagation protocol of M. oleifera using nodal segment as explant while maintaining genomic stability.

\subsection{Materials And Methods}

\subsection{Acquisition and establishment of explants}

Plant samples were procured from the maintained collection of $M$. oleifera in the botanical garden of Faculty of Tropical AgriSciences (FTZ), Czech University of Life Sciences, Prague. Healthy plants were selected for explant excision. New branches having nodal segments were utilized as explants.

\subsection{Surface sterilization of explants}

Firstly, explants containing 3-4 nodes were washed in running distilled water for 10min. This was followed by immersing the explants in $70 \%$ ethanol $(\mathrm{V} / \mathrm{V})$ for $2 \mathrm{~min}$, then $1 \%$ solution of sodium hypochlorite $(\mathrm{V} / \mathrm{V})(\mathrm{NaClO}$, commercial bleach-SAVO, containing two drops of tween 20 for $10 \mathrm{~min}$. Subsequently, the explants were rinsed in sterile distilled water thrice and a rotary shaker was used for all rinses and surface sterilization. Thereafter, the sterile explants were transferred to the laminar flow hood for initiation. The percentage of clean culture were recorded after 14 days of inoculation.

\subsection{Preparation of culture medium}

Murashige and Skoog's (1962) basal medium was prepared by adding appropriate quantities of major and minor nutrients, vitamins, sucrose, myo-inositol, and agar to distilled water. The mixture was constantly stirred using a magnetic stirrer and when uniformity was achieved, the $\mathrm{pH}$ of the medium was adjusted to $5.7 \pm 1$. With continuous stirring, approx. $25-30 \mathrm{ml}$ prepared media was dispensed into $100 \mathrm{ml}$ conical flasks, supplemented with respective growth regulators. The conical flasks containing media were then covered using aluminium foil and sealed with parafilm. Finally, the media was sterilized in an autoclave (Nuve $0 \mathrm{~T}-032 \mathrm{model}$ ) at $121^{\circ} \mathrm{C}$ for $20 \mathrm{~min}$ before cooling and solidifying into a gel for proper explant anchorage.

\subsection{Plant Growth Regulators treatment}

The treatments consisted of five different shoot induction media containing BAP, TDZ, Kinetin, Zeatin and N6-(2-isopentyl)adenine (2iP) at three concentrations $(0.1,0.5$ and $1.0 \mathrm{mg} / \mathrm{L})$ along with $\mathrm{MS}$ basal medium as control $(0.0 \mathrm{mg} / \mathrm{L}$ of growth regulator). After five subsequent transfers (sub-culturing), in-vitro derived shoots were then transferred to root induction media with varying concentrations of Indole-3- 
acetic acid (IAA) $(0.0,0.1,0.5$ and $1.0 \mathrm{mg} / \mathrm{L})$. Accordingly, each treatment comprised of a minimum of 20 sampling units replicated three times.

\subsection{Culture condition}

The cultures were incubated in growth rooms at $24 / 20 \pm 1^{\circ} \mathrm{C}$ and a $16 / 8 \mathrm{~h}$ (light/dark) photoperiod under white fluorescent lamps providing a light intensity of $25001 x$. The relative humidity of the rooms was maintained between $65-70 \%$.

\subsection{Ex-Vitro Transfer}

In-vitro rooted explants were carefully removed from the growth media, washed with distilled water to remove adhering medium, and transferred into plastic pots containing sterile soil substrate and perlite in a ratio of 3:1 $(\mathrm{v} / \mathrm{V})$. Acclimatization was achieved by housing the plants under transparent polythene covering for 7 days while maintaining a high humidity in the chamber. The plants with pots were removed from the chamber and are kept under ambient conditions.

\subsection{Flow cytometry analysis}

Small sections of leaf sample ( $1 \mathrm{~cm}^{2}$ approx.) were chopped with a sharp razor blade in a petri dish containing $1 \mathrm{ml}$ of Otto I buffer $\left(0.5 \%\right.$ Tween $\left.20,0.1 \mathrm{M} \mathrm{C}_{6} \mathrm{H}_{8} \mathrm{O}_{7}\right)$. The resultant suspension was then filtered through a $50 \mu \mathrm{M}$ nylon mesh. Subsequently, $1 \mathrm{ml}$ of Otto II buffer containing 4',6-diamidino-2phenylindole (DAPI) $(2 \mu \mathrm{g} / \mathrm{mL})$ and $15 \mathrm{mM} \beta$-mercaptoethanol was added to the filtered sample solutions. A minimum of 10000 nuclei was recorded using the Partec PAS flow cytometer. Flomax software package (Version 2.3) was used to generate and evaluate the histogram of DNA content. The donor mother plant served as an internal standard. Random propagated plants were selected and utilized to assess genomic size stability. A minimum of 20 measurements was taken. Additionally, combined measurements were taken by chopping leaf samples from mother and micro propagated plants together.

\subsection{Data collection and statistical analysis}

After inoculation on shoot proliferation media, culture was maintained for 30 days before recording data on shoot growth and 15 days for root growth on rooting media. Growth parameters examined included the percentage of shoot regeneration and their numbers, shoot length, root numbers and lengths. All the recorded data were analyzed by Analysis of variance (ANOVA), followed by post-hoc assessment using Duncan's multiple range test at $5 \%$ significance.

\subsection{Results And Discussion}

\section{Influence of cytokinins on shoot number and length}

It is a well-known fact that cytokinins play a vital role in shoot organogenesis (Hill and Schaller, 2013). In this study, the response of $M$. oleifera nodal explants to different cytokinins was tested (Table S1). The 
mean number of shoots per explant increased exponentially with the increasing concentration of all cytokinins studied (Fig. 1B). The only exception to this trend was in the explants treated with TDZ, where increment in concentration produced no shoots at all, rather had a detrimental effect on the explant (Fig. 1B, 2C). The highest number of shoots was observed in media supplemented with $1.0 \mathrm{mg} / \mathrm{L}$ of BAP producing an average of $8.0 \pm 1.20$ shoots per explant (Fig. 1B). In addition to BAP, kinetin at a higher concentration of $1 \mathrm{mg} / \mathrm{L}$ also performed significantly well when compared to control in inducing new shoots up to $4.6 \pm 2.53$ per explant(Table S1). Further, the highest shoot length was achieved by kinetin at the concentration of $1 \mathrm{mg} / \mathrm{L}$ producing a maximum average shoot length of $4.0 \pm 1.65 \mathrm{~cm}$ followed by BAP at a concentration of $1 \mathrm{mg} / \mathrm{L}$ that generated a maximum average shoot length of $3.9 \pm 0.84 \mathrm{~cm}$ (Fig. 1A). Although, the difference was statistically not significant (Table S1). Another trend that followed in all treatments was callusing at the base of the explants regardless of the cytokinin used, excluding the control (basic MS) (Fig. 2). Kinetin at lower concentrations, zeatin, TDZ and 2ip either produced statistically similar or lower number and length of shoots compared to the control. Furthermore, the survival rate among all treatments ranged between $80-100 \%$ except TDZ, where the survival rate was merely $10 \%$ at lower concentration and no explant survived at higher concentrations (Table S1).

In our study, BAP was found to be most effective in inducing multiple shoots. The trend of increasing shoot number in $M$. oleifera with increasing BAP concentration has been reported in several studies (Gayathri et al., 2015, Saini et al., 2012, Ridzuan et al., 2018). Additionally, a study by Ridzuan et al., 2019 found that the number of shoots increased with increasing levels of BAP up to $1 \mathrm{mg} / \mathrm{L}$ which concurs with the results of the current study. Although, further increase in the concentration up to $3 \mathrm{mg} / \mathrm{L}$ resulted in a short and fewer number of shoots. In another study conducted by Saini et al., 2012 from nodal segments of $M$. oleifera grown on MS media containing $1 \mathrm{mg} / \mathrm{l}$ BAP produced up to $9.0 \pm 1.0$ shoots per explant. However, the value dropped to $2.6 \pm 0.5$ and $2.3 \pm 0.58$ shoots per explant when the BAP was combined with Naphthaleneacetic acid (NAA) at $0.5 \mathrm{mg} / \mathrm{L}$ and $1 \mathrm{mg} / \mathrm{L}$ respectively. To that effect, several authors assert that plant growth regulators play antagonistic and synergistic roles to each other (Danilova, 2020). This means that the presence of auxins could have restrained the shoot enhancement abilities of cytokinin in those studies. Overall, from current and previous studies, it appears that BAP alone at a concentration of $1 \mathrm{mg} / \mathrm{L}$ is optimum for multiple shoot induction in this plant species.

On the other hand, shoot length was effectively influenced by kinetin and was better than that of BAP but the difference was not significant between them. Even though the length of the shoots was higher, kinetin failed to produce a higher number of shoots in comparison to BAP (Fig. 1B). Moreover, it did not perform well in any of the previous studies on M. oleifera micropropagation when compared to BAP (Marfori, 2010, Abdullah et al., 2019). Recently, TDZ was also employed to assess its effect on shoot regeneration in $M$. oleifera. Concurring to the current study, no shoots were generated rather produced a high amount of callusing (Ridzuan et al., 2019). Similarly, several studies have reported TDZ to have an abnormal and detrimental effect on explants with increasing concentration (Dewir et al., 2006; Ivanova and van Staden 2008; Dewir et al., 2018). 
In addition, zeatin and 2ip were also tested for their ability to induce and proliferation shoots. Although zeatin at all concentrations was able to produce a similar number of shoots as the control, it did not affect the shoot length of the explant and remained constant between all concentrations. Similarly, 2iP at all concentrations produced a similar number of shoots as the control, but it affected shoot length poorly and produced shorter shoots among all the treatments studied except TDZ.

\section{Effect of auxin IAA on root induction}

Normally, auxins are known to increase overall rooting percentages, produce more roots of better quality, speed up the process of root initiation in addition to consistent rooting (Hartmann et al. 2002; Blythe et al. 2007). In the current study, three concentrations of IAA were tested for inducing roots. All the concentrations of IAA were successful in inducing roots with the increasing concentration (Fig. 1C, 1D). The average number of roots and root length of $4.9 \pm 1.43 \mathrm{~cm}$ and $5.3 \pm 3.06 \mathrm{~cm}$ respectively was achieved at the concentration of $1 \mathrm{mg} / \mathrm{L}$ of IAA. Lower concentrations either produced statistically similar or lower number and length of roots compared to the control. However, the best rooting parameters were exhibited when in-vitro grown shoots were cultured on basic MS media producing an average number of roots and root length of $4.9 \pm 0.94 \mathrm{~cm}$ and $6.0 \pm 1.62 \mathrm{~cm}$ respectively (Table S2). Although this result was not significantly different from IAA incorporation at $1.0 \mathrm{mg} / \mathrm{L}$, it indicates that the level of endogenous auxin in the transferred shoots of $M$. oleifera was sufficient for optimal root induction.

Reports from similar studies have provided differing results. For instance, a study by Gupta et al., 2020, reported that IAA at a lower concentration of $0.1 \mathrm{mg} / \mathrm{L}$ was effective in inducing rooting than higher concentration. On the other hand, a higher concentration of $1.75 \mathrm{mg} / \mathrm{L}$ of IAA was found to be more effective in a study by Shokoohmand and Drew, 2013. Differing from these findings, effective rooting was observed on the basic MS in the current study. A similar observation was also made by Islam et al. 2005 who reported optimum rooting without using growth regulators in this plant species.

The disparity between these reports could be due to genetic differences as different genotypes respond otherwise under similar conditions (Hartmann et al. 2002). These variations may also result from the invitro grown shoots having differing levels of juvenility. According to Blythe et al. 2007, juvenile plants are more responsive to auxin application than older plants. This means that the physiological state of the explant is very crucial in determining the level of rooting success. Even though longer roots indicate better rooting success, it may not necessarily translate to overall propagation success. This is because longer roots require more delicate handling during transplanting prior to hardening. Hence there is a potential risk of the roots breaking or getting damaged.

\section{Ex-Vitro transfer and acclimatization}

After successful in-vitro growth, the plants were transferred to the greenhouse for primary and secondary hardening. Due to the use of the transparent polythene covering for 7 days, a survival rate of $100 \%$ was achieved (Fig. 3). This result was better than what was recorded by Ochieng (2020), Adugna et al., 2020, Feyissa and Mamo (2019), and Avila-Treviño et al., 2017 who achieved survival rates of 55, 76, 90 and 
$95 \%$ respectively in this plant species. It appears that the use of the polythene covering contributed to achieving a better success rate than previous studies. However, a similar method was also used by Saini et al., 2012 where plants were kept in soil under transparent polythene for 15 days achieving a success rate of $80 \%$. Unlike the current study, the long duration of 15 days in the polythene chamber and the use of soil for hardening might be the reason behind this lower success rate.

\section{Flow cytometry analysis}

One of the shortcomings of tissue culture is the occurrence of somaclonal variation within in-vitro derived plantlets. Therefore, the use of flow cytometry analysis to control genomic size is desirable, especially for plants of therapeutic compounds as their presence, composition and concentration should remain unchanged after micropropagation. Hence, flow cytometry was deployed to determine the genomic stability of $M$. oleifera regenerants. The results suggest that no aberrant plants were produced from the nodal explants regardless of the stage of sampling. This means that plants at all the stages assessed, generated gnomically stable plants as exhibited by single peaks attained at the gain value of 288 among measured samples (Fig. 4). The combination of donor and the micropropagated plants also resulted in a similar single peak suggesting no variation among them (Fig. 4). To the best of our knowledge, this is the first study to utilize flowcytometry to assess the genomic stability in micropropagated Moringa oleifera regenerants. Moreover, none of the previous studies on micropropagation of this species utilized any form of genetic analysis to assess the genomic stability except Avila-Treviño et al., 2017. Nonetheless, flowcytometry has been utilized in numerous other plant species like Juniperus phoenicea by Loureiro et al., 2007 where genomic size stability was assessed of the plantlets following in-vitro multiplication and all plants produced were of uniform genomic size and had similar DNA content.

\section{Conclusion}

The surface sterilization protocol deployed in this study was sufficient to obtain contamination-free sterile culture without affecting the explants. Among five cytokinins studied, BAP at $1 \mathrm{mg} / \mathrm{L}$ induced optimum shoots and is comparable to previous studies. Basic MS without auxin was found to be effective for root induction. Moreover, a 100\% survival rate was achieved after ex-vitro transfer of the plantlets owing to the use of polythene coving for 7 days. Additionally, the assessment of genomic size stability did not show any variation between the mother plant and in-vitro plantlets. Overall, a reliable protocol for mass propagation of $M$. oleifera was established and this can further contribute to the future conservation and breeding efforts in this plant species.

\section{Declarations}

\section{Data availability}

The data supporting the findings of the current study are available within the article. 
Code availability

Not applicable.

\section{Acknowledgements}

This research was funded by the Internal Grant Agency of FTA, grant number 20213105 Czech University of Life Sciences Prague, the Czech Republic. Additionally, RB is thankful to Madhab Kumar Sen, PhD Scholar, Czech University of life sciences, Prague for his valuable guidance.

\section{Author information}

\section{Affiliations}

Department of Crop Sciences and Agroforestry, Faculty of Agrobiology, Faculty of Tropical AgriSciences, Czech University of Life Sciences Prague, Kamýcká 129, 16521 Prague 6 - Suchdol, Czech Republic.

Rohit Bharati (https://orcid.org/0000-0001-5989-6153), Moses Okao, Eloy Fernández-Cusimamani (https://orcid.org/00-0001-7835-9310)

Department of Agroecology and Crop Production, Faculty of Agrobiology, Food and Natural Resources, Czech University of Life Sciences Prague, Kamýcká 129, 16521 Prague 6 - Suchdol, Czech Republic.

Katerina Hamouzová

\section{Contributions}

RB conceived the study, designed, and executed the experiments. OM and RB wrote the manuscript. Statistical analysis was performed by KH. EFC was responsible for formal analysis, visualization, supervision, consultations. All the authors have read and approved the final version of the manuscript.

\section{Corresponding author}

Correspondence to E-mail address: eloy@ftz.czu.cz (E. Fernández-Cusimamani)

Ethics declarations

Conflict of interest

The authors declare that they have no conflicts of interest relevant to the content of this article.

\section{Ethical approval}

Not applicable. 
Not applicable.

\section{Consent to publication}

All authors consent to the publication of this manuscript.

\section{References}

1. Abdullah, E. N., HASSANEIN, A., SALEM, J., \& FAHEED, F. (2019). Some important aspects in Moringa oleifera Lam. Micropropagation. Acta agriculturae Slovenica, 113(1), 13-27.

2. Adugna, A.Y., Feyissa, T. \& Tasew, F.S. Optimization of growth regulators on in vitro propagation of Moringa stenopetala from shoot explants. BMC Biotechnol 20, 60 (2020). https://doi.org/10.1186/s12896-020-00651-w.

3. Anjorin TS, Ikokoh P, Okolo S (2010). Mineral composition of Moringa oleifera leaves, pods and seeds from two regions in Abuja, Nigeria. Int. J. Agric Biol., 12: 431-434.

4. Anwar F, Sajid L, Muhammad A, Anwarul HG (2007). Moringa oleifera: A Food plant with Multiple Medicinal Uses. Phytother. Res., 21: 17- 25.

5. Avila-Treviño J.A., Muñoz-Alemán J.M., Pérez-Molphe-Balch E., Rodríguez-Sahagún A., MoralesDomínguez J.F. 2017. In vitro propagation from bud and apex explants of Moringa oleifera and evaluation of the genetic stability with RAMP marker. South African Journal of Botany 108 (2017) 149-156. https://doi.org/10.1016/j.sajb.2016.10.003.

6. Blythe E.K., Sibley J.L, Tilt K.M., and Ruter J.M. (2007) Methods of auxin application in cutting propagation: A Review of 70 years of scientific discovery and commercial practice. J. Environ. Hort. 25(3): 166-179.

7. Clarindo, W., de Carvalho, C., Araújo, F., de Abreu, I., \& Otoni, W. (2007). Recovering polyploid papaya in vitro regenerants as screened by flow cytometry. Plant Cell, Tissue And Organ Culture, 92(2), 207214. doi: 10.1007/s11240-007-9325-1

8. Danilova, M.N.; Doroshenko, A.S.; Kudryakova, N.V.; Klepikova, A.V.; Shtratnikova, V.Y.; Kusnetsov, V.V. The Crosstalk Between Cytokinin and Auxin Signaling Pathways in the Control of Natural Senescence of Arabidopsis thaliana Leaves. Russ. J. Plant Physiol.2020, 67, 1028-1035.

9. Daghaghele, S., Kiasat, A. R., Safieddin Ardebili, S. M., \& Mirzajani, R. (2021). Intensification of Extraction of Antioxidant Compounds from Moringa Oleifera Leaves Using Ultrasound-Assisted Approach: BBD-RSM Design. International Journal of Fruit Science, 21(1), 693-705.

10. Delporte, F., Muhovski, Y., Pretova, A., \& Watillon, B. (2013). Analysis of expression profiles of selected genes associated with the regenerative property and the receptivity to gene transfer during somatic embryogenesis in Triticum aestivum L. Molecular biology reports, 40(10), 5883-5906.

11. Dewir, Y. H., Chakrabarty, D., Hahn, E. J., \& Paek, K. Y. (2006). A simple method for mass propagation of Spathiphyllum cannifolium using an airlift bioreactor. In Vitro Cellular \& Developmental BiologyPlant, 42(3), 291-297. 
12. Dewir, Y. H., Naidoo, Y., \& da Silva, J. A. T. (2018). Thidiazuron-induced abnormalities in plant tissue cultures. Plant cell reports, 37(11), 1451-1470.

13. Fahey, J. W. (2005). Moringa oleifera: a review of the medical evidence for its nutritional, therapeutic, and prophylactic properties. Part 1. Trees for life Journal, 1(5), 1-15.

14. Feyissa. T and Mamo. M. 2019. In vitro regeneration of Moringa oleifera Lam. from leaf explants. SINET: Ethiop. J. Sci., 42(2):42-49, 2019.

15. Förster, N., Mewis, I., \& Ulrichs, C. (2013). Moringa oleifera-establishment and multiplication of different ecotypes in vitro. Gesunde Pflanzen, 65(1), 21-31.

16. Fotouo-M, H., du Toit, E. S., \& Robbertse, P. J. (2015). Germination and ultrastructural studies of seeds produced by a fast-growing, drought-resistant tree: implications for its domestication and seed storage. AoB Plants, 7.

17. Ganatra, T., Payal, B., Umang, J. and Tirgar, P. (2012). A panoramic view on pharmacognostic, pharmacological, nutritional, therapeutic and prophylactic values of Moringa oleifera Lam. Int. Res. J. Pharm. 3(6):1-7.

18. Gayathri, M., Kumar, P. S., Prabha, A. M. L., \& Muralitharan, G. (2015). In vitro regeneration of Arachis hypogaea L. and Moringa oleifera Lam. using extracellular phytohormones from Aphanothece sp. MBDU 515. Algal Research, 7, 100-105.

19. Hartmann, H.T., D.E. Kester, F.T. Davies, Jr., and R.L. Geneve. 2002. Hartmann and Kester's Plant Propagation: Principles and Practices. 7th ed. Prentice Hall, Upper Saddle River, NJ.

20. Hill, K., \& Schaller, G. E. (2013). Enhancing plant regeneration in tissue culture: a molecular approach through manipulation of cytokinin sensitivity. Plant signaling \& behavior, 8(10), 10.4161/psb.25709. https://doi.org/10.4161/psb.25709.

21. Islam, S., Jahan, M. A. A., \& Khatun, R. (2005). In vitro regeneration and multiplication of year-round fruit-bearing Moringa oleifera $L$ (No. RESEARCH).

22. Islam, S., Jahan, M. A. A., \& Khatun, R. (2005). In vitro regeneration and multiplication of year-round fruit-bearing Moringa oleifera L (No. RESEARCH).J Agric Food Chem

23. Ivanova, M., \& van Staden, J. (2008). Effect of ammonium ions and cytokinins on hyperhydricity and multiplication rate of in vitro regenerated shoots of Aloe polyphylla. Plant Cell, Tissue and Organ Culture, 92(2), 227-231.

24. Jamsheed, S., Rasool, S., Koul, S., Azooz, M. M., \& Ahmad, P. (2013). Crop improvement through plant tissue culture. In Crop Improvement (pp. 123-148). Springer, Boston, MA.

25. Jun-jie, Z., Yue-sheng, Y., Meng-fei, L., Shu-qi, L., Yi, T., Han-bin, C., \& Xiao-yang, C. (2017). An efficient micropropagation protocol for direct organogenesis from leaf explants of an economically valuable plant, drumstick (Moringa oleifera Lam.). Industrial Crops and Products, 103, 59-63.

26. Loureiro, J., Capelo, A., Brito, G., Rodriguez, E., Silva, S., Pinto, G., \& Santos, C. (2007). Micropropagation of Juniperus phoenicea from adult plant explants and analysis of ploidy stability using flow cytometry. Biologia Plantarum, 51(1), 7-14. 
27. Mamedes-Rodrigues, T. C., Batista, D. S., Vieira, N. M., Matos, E. M., Fernandes, D., Nunes-Nesi, A., ... \& Otoni, W. C. (2018). Regenerative potential, metabolic profile, and genetic stability of Brachypodium distachyon embryogenic calli as affected by successive subcultures. Protoplasma, 255(2), 655-667.

28. Mehwish, H. M., Rajoka, M. S. R., Xiong, Y., Cai, H., Aadil, R. M., Mahmood, Q., ... \& Zhu, Q. (2021). Green synthesis of a silver nanoparticle using Moringa oleifera seed and its applications for antimicrobial and sun-light mediated photocatalytic water detoxification. Journal of Environmental Chemical Engineering, 9(4), 105290.

29. Maqsood, M., Qureshi, R., Arshad, M., Ahmed, M. S., \& Ikram, M. (2017). Preliminary phytochemical screening, antifungal and cytotoxic activities of leaves extract of Moringa oleifera Lam. from Salt range, Pakistan. Pak. J. Bot, 49(1), 353-359.

30. Marfori, E.C., 2010. Clonal micropropagation of Moringa oleifera L. Philipp Agric. Sci. 93, 454-457.

31. Mathur, M., Yadav, S., Katariya, P. K., \& Kamal, R. (2014). In vitro propagation and biosynthesis of steroidal sapogenins from various morphogenetic stages of Moringa oleifera Lam., and their antioxidant potential. Acta physiologiae plantarum, 36(7), 1749-1762.

32. Murashige T., Skoog F., 1962. A revised medium for rapid growth and bioassays with tobacco tissue cultures. Physiologya Plantarum, 15: 473-497.

33. Nouman, W., Siddiqui, M., Maqsood, S., Basra, A., Afzal, I., and Rehman, H. (2012). Enhancement of emergence potential and stand establishment of Moringa oleifera Lam. by seed priming. Turkish Journal of Agriculture and Forestry. 36. 227-235. 10.3906/tar-1103-39.

34. Ochieng K.O (2020) Tissue culture of Moringa oleifera Lam. and determination of antifungal activity of its callus extracts. Masters Thesis. University of Nairobi. Accessed at http://erepository.uonbi.ac.ke/ on $1^{\text {st }}$ November 2021.

35. Olson, M. E., \& Carlquist, S. (2001). Stem and root anatomical correlations with life form diversity, ecology, and systematics in Moringa (Moringaceae). Botanical Journal of the Linnean Society, 135(4), 315-348.

36. Pandey, A., Pradheep, K., Gupta, R., Nayar, E. R., \& Bhandari, D. C. (2011). 'Drumstick tree'(Moringa oleifera Lam.): a multipurpose potential species in India. Genetic Resources and Crop Evolution, 58(3), 453-460.

37. Ramachandran, C., Peter K.V., Gopalakrishnan, P.K. 1980. Drumstick (Moringa oleifera): A multipurpose tree Indian vegetable. Economic Botany. 34 (3): 276-283.

38. Ridzuan, N. I., Abdullah, N., Vun, Y. L., \& Supramaniam, C. V. (2020). Micropropagation and defence enzymes assessment of Moringa oleifera L. plantlets using nodal segments as explant. South African Journal of Botany, 129, 56-61.

39. Rout, G. R., Mohapatra, A., \& Jain, S. M. (2006). Tissue culture of ornamental pot plant: A critical review on present scenario and future prospects. Biotechnology advances, 24(6), 531-560.

40. Ružić, Dj. V, and Vujović, T. I. 2008 The effects of cytokinin types and their concentration on in vitro multiplication of sweet cherry cv. Lapins (Prunus avium L.). Hort. Sci. (Prague), 35, 2008 (1): 12-21. 
41. Saini, R. K., Shetty, N. P., Giridhar, P., \& Ravishankar, G. A. (2012). Rapid in vitro regeneration method for Moringa oleifera and performance evaluation of field grown nutritionally enriched tissue cultured plants. 3 Biotech, 2(3), 187-192. https://doi.org/10.1007/s13205-012-0045-9.

42. Salem J. M. 2016. In vitro propagation of Moringa Oleifera L. under salinity and ventilation conditions. Genetics and Plant Physiology. 6: 1-2, pp. 54-64.

43. Schoenfelder, K. P., \& Fox, D. T. (2015). The expanding implications of polyploidy. Journal of Cell Biology, 209(4), 485-491.

44. Sharma, G. K., \& Raina, V. (1982). Propagation techniques of Moringa oleifera Lam. In Improvement of forest biomass: symposium proceedings/edited by PK Khosla. Solan, India: Indian Society of Tree Scientists, c1982.

45. Shokoohmand, A., \& Drew, R. A. (2011, October). Micropropagation of Moringa oleifera. In $V$ International Symposium on Acclimatization and Establishment of Micropropagated Plants 988 (pp. 149-160).

46. Sharma, G.K., Raina, V. 1982. Propagation techniques of Moringa oleifera Lam. In: Khosla, P.K., ed., Improvement of forest biomass: Proceedings of a symposium: 1980 November 20-21; Solan, India. Indian Society of Tree Scientists: 175-181.

47. Siddhuraju P, Becker K. 2003. Antioxidant properties of various solvent extracts of total phenolic constituents from threedifferent agro-climatic origins of drumstick tree (Moringaoleifera Lam.). J Agric Food Chem 15: 2144-2155.

48. Skoog F, Miller C.O. 1957. Chemical regulation of growth and organ formation in plant tissues cultured in vitro. Symp Soc Exp Biol.; 11:118-30.

49. Sliwinska, E., \& Thiem, B. (2007). Genome size stability in six medicinal plant species propagated in vitro. Biologia Plantarum, 51(3), 556-558.

50. Xiong, Y., Rajoka, M. S. R., Mehwish, H. M., Zhang, M., Liang, N., Li, C., \& He, Z. (2021). Virucidal activity of Moringa A from Moringa oleifera seeds against Influenza A Viruses by regulating TFEB. International Immunopharmacology, 95, 107561.

51. Zafar, N., Mujib, A., Ali, M., Tonk, D., Gulzar, B., Malik, M., ... \& Mamgain, J. (2019). Genome size analysis of field grown and tissue culture regenerated Rauvolfia serpentina (L) by flow cytometry: histology and scanning electron microscopic study for in vitro morphogenesis. Industrial Crops and Products, 128, 545-555.

52. Zhao, Z.; Andersen, S.U.; Ljung, K.; Dolezal, K.; Miotk, A.; Schultheiss, S.J.; Lohmann, J.U. Hormonal Control of the Shoot Stem-Cell Niche. Nat. Cell Biol. 2010, 465, 1089-1092.

\section{Figures}


A)

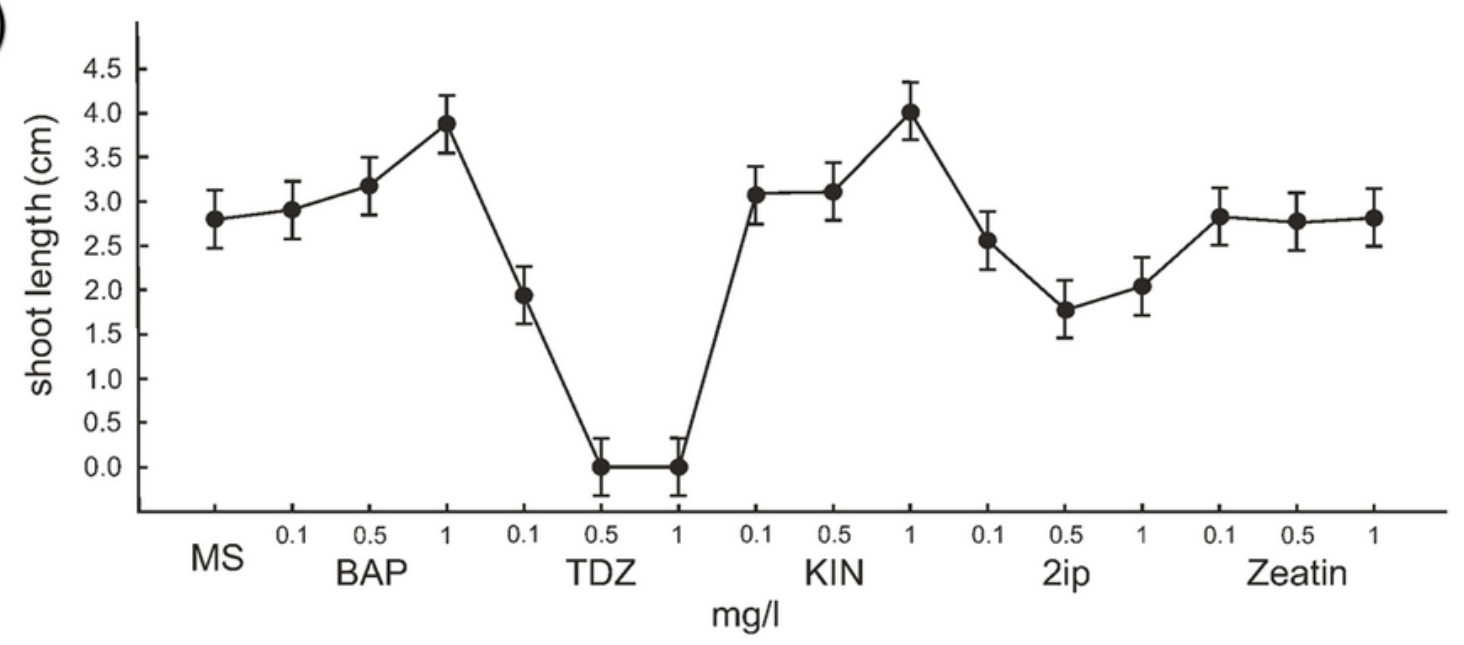

B)

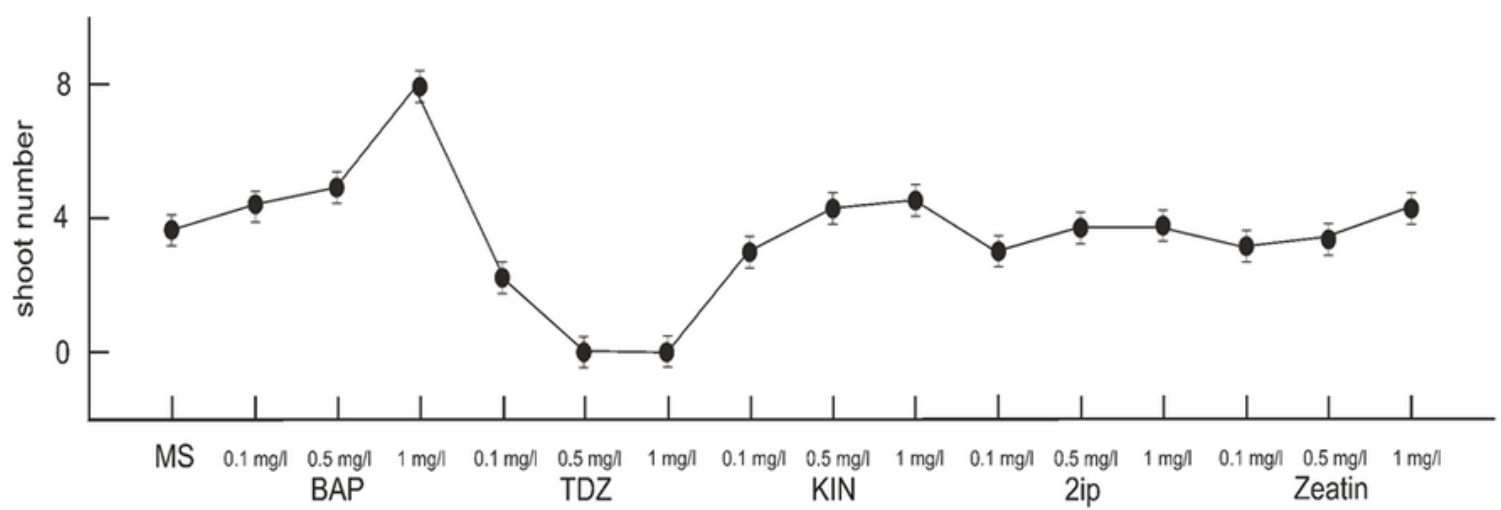

C)

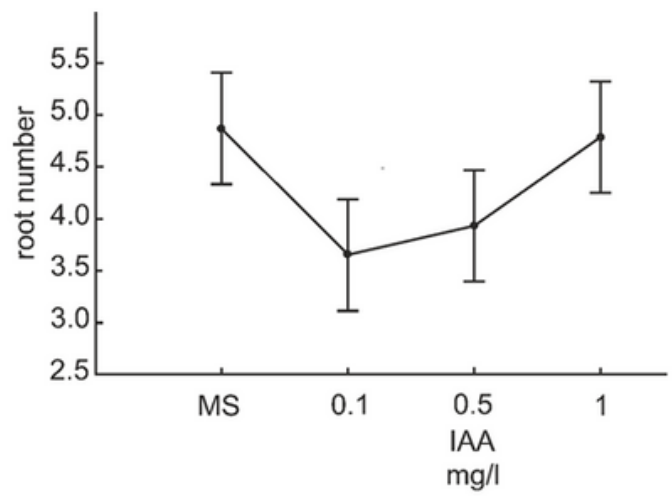

D)

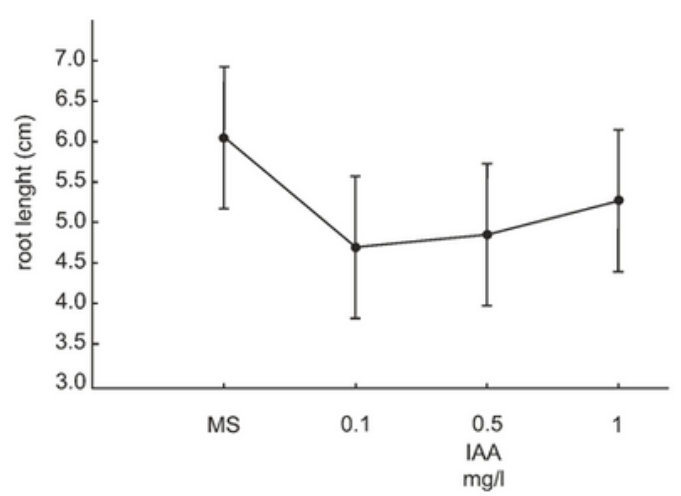

Figure 1

Influence of various PGRs on A) Shoot length B) Shoot number C) root number D) root length of $M$. oleifera explants in comparison to control (Basic MS). 
A.

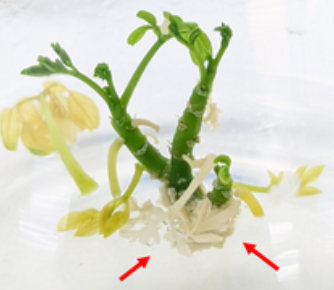

D.

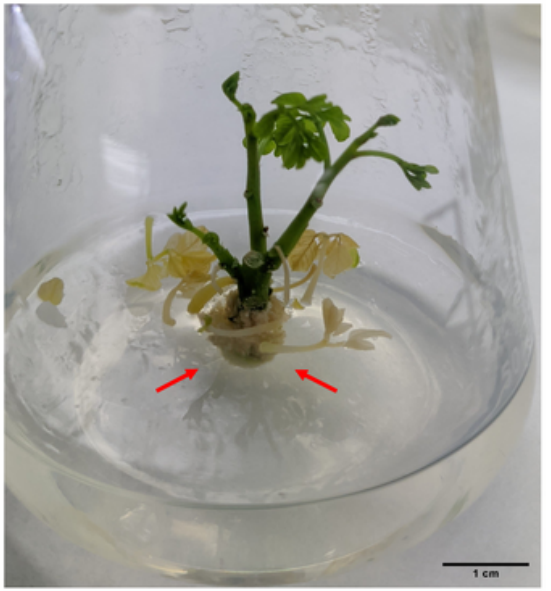

B.

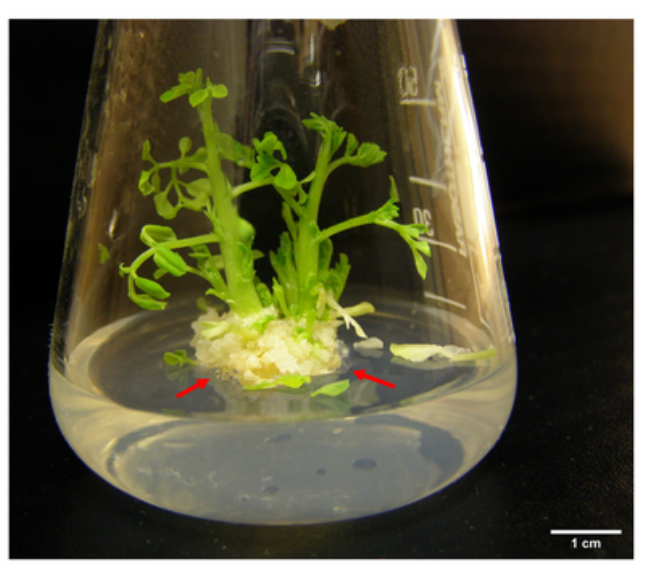

E.

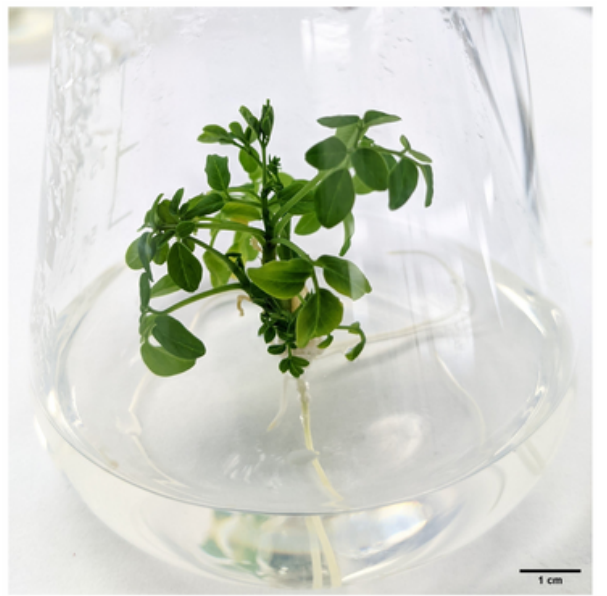

C.

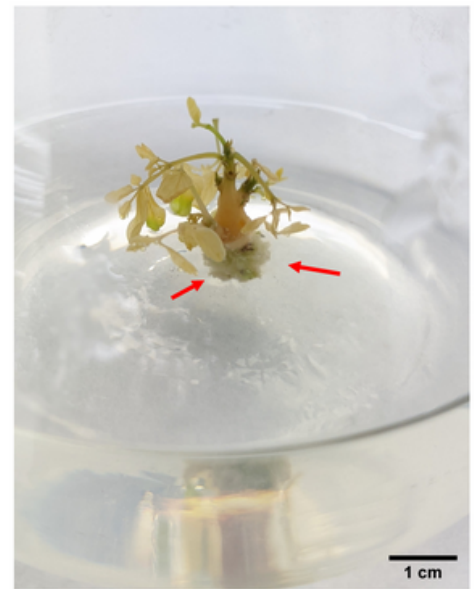

F.

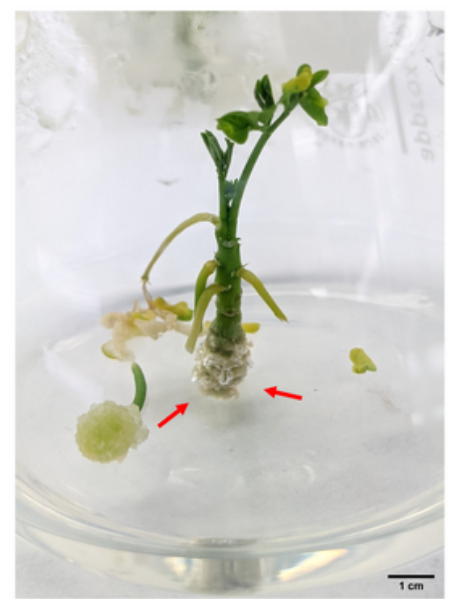

Figure 2

Explant of $M$. oleifera subjected to A) 2ip; B) BAP; C) TDZ; D) Kinetin; E) MS only and F) Zeatin. Callusing at the base of explants pointed by arrows (red).

A)

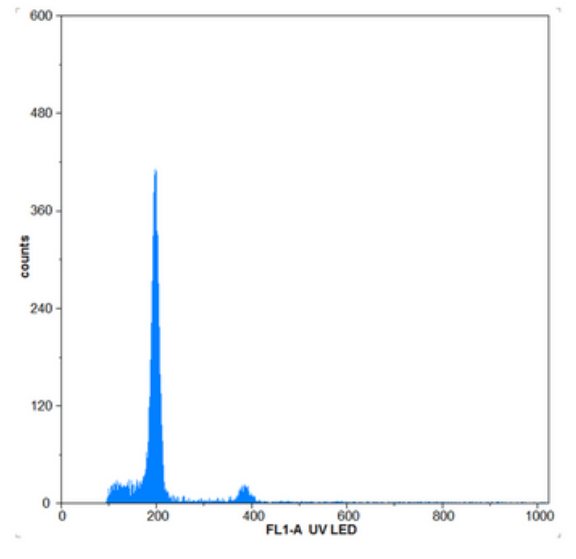

B)

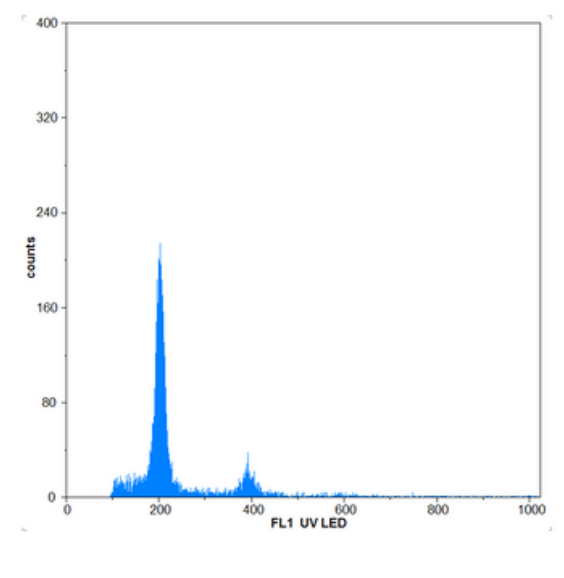

C)

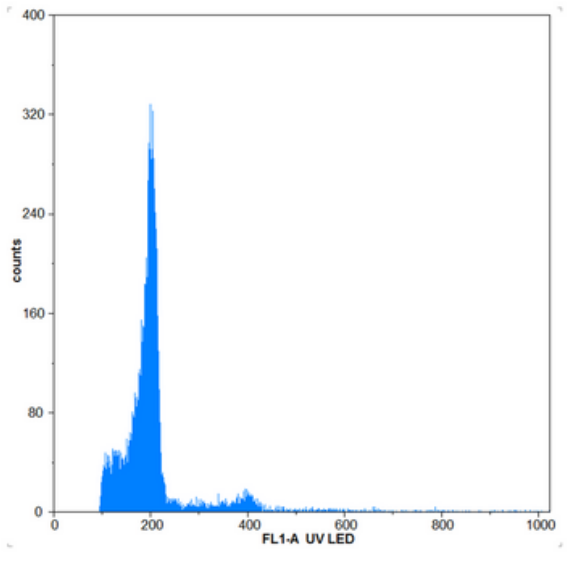




\section{Figure 3}

Micropropagated plantlets of $M$. oleifera after successful acclimatization of A) 7 days (primary hardening) and B) 30 days (secondary hardening).
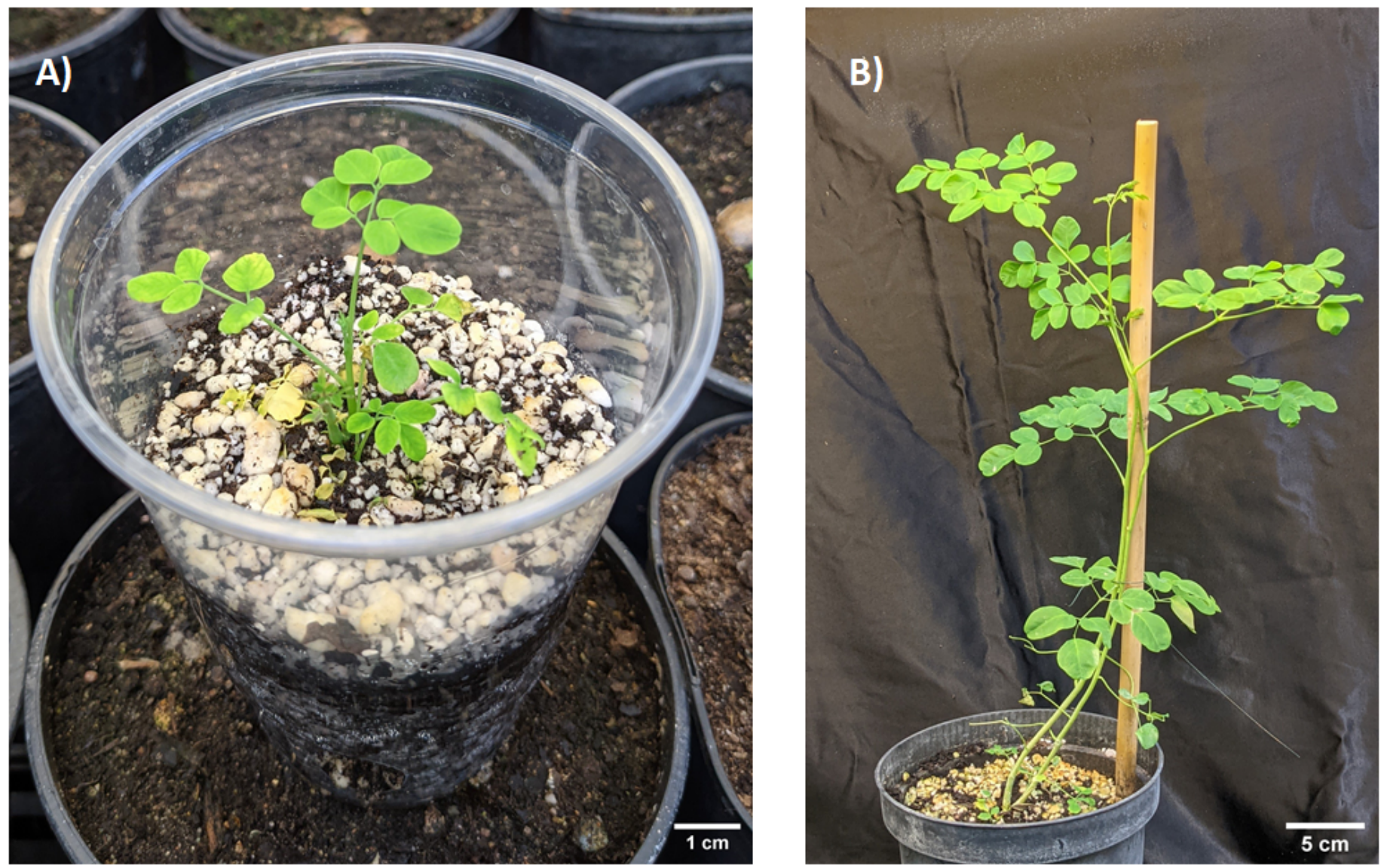

Figure 4

Histogram with peak of relative DNA content of M.oleifera after analysis of nuclei isolated from A) Donor plant B) Micropropagated plant and C) Combination of donor and micropropagated plant, stained with 4',6-diamidino-2-phenylindole (DAPI).

\section{Supplementary Files}

This is a list of supplementary files associated with this preprint. Click to download.

- Supplementary.docx 